\title{
BRI-Analysis of the East-Coast Rail Line (ECRL) in Malaysia
}

\author{
Kehao Chang ${ }^{1, \dagger}$, Jiantao $\mathrm{Lu}^{2, \dagger}$, Jing Sui ${ }^{3,}{ }^{*}, \dagger$ \\ ${ }^{1}$ Department of international economy, China Foreign Affairs University, Beijing 102206, China \\ 2Pegasus California School, Qingdao 266200, China \\ ${ }^{3}$ Department of Economics and Management, Beijing University of Technology, Beijing 100124, \\ China
}

*Corresponding author. Email: guanghua.ren@gecacademy.cn

\section{tThese authors contributed equally}

\begin{abstract}
In recent years, China has put forward the Belt and Road Initiative and conducted cooperation with neighboring countries in various aspects. This paper will focus on the analysis of ECRL in which China participates in cooperative construction. Due to financing difficulties and political problems in Malaysia, the project took a long time to negotiate. At the same time, the Malaysian media and people have maintained a positive attitude towards the project because it will bring long-term benefits to both China and Malaysia's political and economic environment. There are also some difficulties in the implementation of this project, which are similar to other projects that China has cooperated with. However, these difficulties can be solved by putting forward countermeasures. Therefore, it reveals that Malaysia must strive to solve internal problems such as inefficiency, low productivity, and corruption. Two countries should unite their minds and strengthen their confidence to build the ECRL into a landmark project of China-Overseas railways. Only in this way can the two countries take the opportunity of the Belt and Road Initiative to promote their cooperative relations and further strengthen economic exchanges between countries.
\end{abstract}

Keywords: BRI; ECRL; political-economic environment.

\section{Introduction}

The Belt and Road Initiative, short for the Silk Road Economic Belt and the 21st Century Maritime Silk Road, was proposed by Chinese President Xi Jinping in September and October 2013. Relying on existing and effective regional cooperation platforms, it aims to actively develop economic cooperation partnerships with countries along the Ancient Silk Road and jointly build a community of political mutual trust, economic integration, and cultural inclusiveness.

As shown in Figure 1, ECRL is planned to connect several key cities in Malaysia, a total length of $665 \mathrm{~km}$. The project, built by China Communications Construction Corporation and financed by the Export-Import Bank of China, will take five to six years to develop in phases and is expected to be completed in 2022. With a total contract value of approximately US\$55 billion, the project is the largest project built by a Chinese company outside of China and the largest single project under the "Belt and Road" initiative. It is an important transportation infrastructure project for Malaysia's EastCoast Economic Zone and will promote Malaysia's coordinated economic and social development. The railroad will connect the important towns on the east coast of Malaysia with the economic centers on the west coast, greatly promoting the development of trade, logistics, import and export, tourism, and other industries and improving the convenience of people's lives.

In November 2016, the Malaysian government and Chinese companies reached a consensus on the financing framework and project construction and signed an agreement worth US\$13.1 billion. 2017 saw the official start of construction of the first phase of ECRL. Malaysian Prime Minister Najib Razak attended the launch ceremony. Here must be mentioned that the 2015 scandal of the Malaysian Development Agency. In his early years as prime minister, Najib implemented political reforms and improved relations with the opposition, including lifting the ban on two political party newspapers published by the opposition and releasing 13 political prisoners. Najib is also advancing his 2008 
Volume 16 (2021)

"1Malaysia" plan, which includes economic, housing and social reforms, and the creation of a stateowned 1 Malaysia Development Berhad (1MDB) to oversee investment and financing operations.

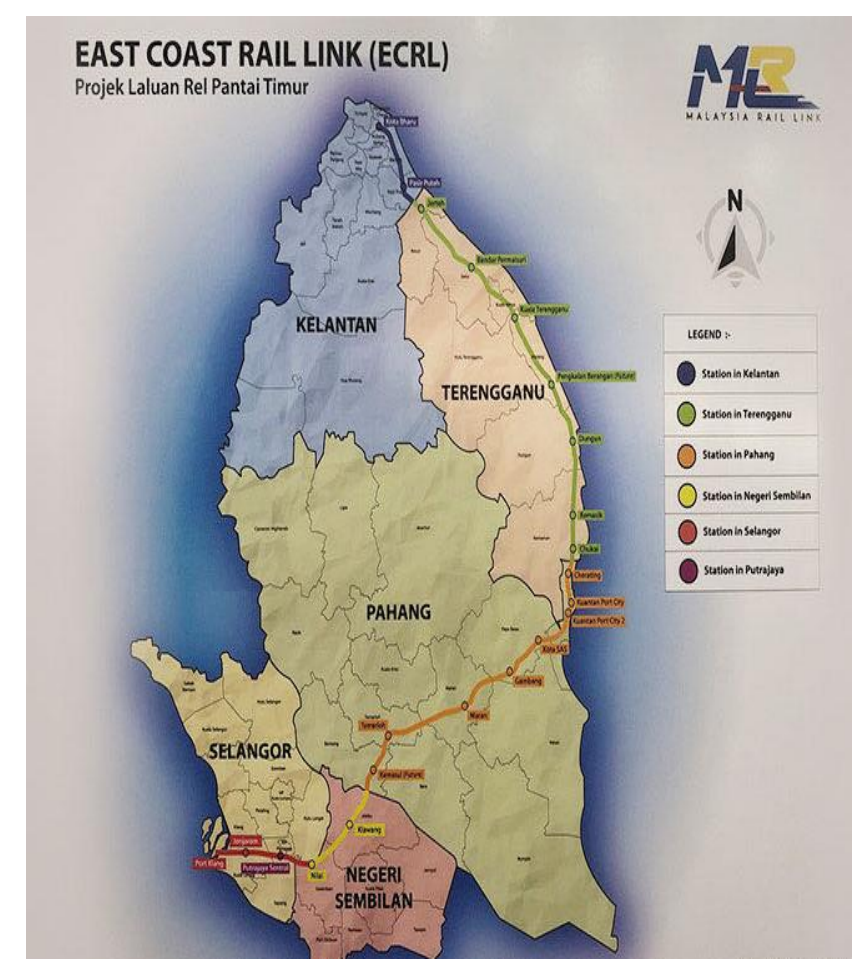

Figure 1 Map of ECRL.

Gong emphasized the importance of Southeast Asia in China's "One Belt, One Road" strategy. Located in the center of India and the Pacific Region, Southeast Asia has long played an important role in China's foreign relations and international security. China encourages Southeast Asian countries to participate in China's Belt and Road construction through policy coordination, trade facilitation, financial integration, infrastructure construction, social exchanges, and other assistance to these developing countries. Two economic corridors run through Southeast Asia, the ChinaIndochina Peninsula Economic Corridor, and the China-Myanmar Economic Corridor. China has also put forward a series of cooperation initiatives [1]. Huang described China's Belt and Road initiative as the country's biggest economic ambition internationally, aiming to boost economic development in Asia, Europe, Africa, and in Europe, mainly through infrastructure construction. The Belt and Road Initiative includes many aspects, including policy dialogue, unimpeded trade, financial support, and people-to-people exchanges. Huang believes that the Belt and Road initiative can turn the region into a pillar of economic vitality. The initiative also faces obstacles, including central coordination mechanisms and different political systems. [2] Malgeri studied the events before and after the 2018 Malaysian election and showed how the Malaysian opposition coalition party strategically used the "China Threat" narrative to challenge the ruling elites. Once in power, how it affects the construction of a large infrastructure project. Malgeri believes that the response of small countries to the Belt and Road Initiative and its results need to consider its complex dynamics. Domestic and international factors, economic, political, and perception variables will all play a role. It also emphasizes the last dimension, demonstrating the extent to which the international community's strong opposition to the Belt and Road Initiative has affected the events under consideration [3].

Tao took the report on the ECRL in the first online news portal of Malaysia as an example, made a comparative analysis of news reports in Chinese and English sections, and considered Malaysian media's views on the image of China and the project. From this, it can be known that the Malaysian media is generally positive about the project. [4] Cao and $\mathrm{Wu}$ analyzed an attitude of news discourse from the perspective of evaluation theory. Research in the new straits times on the east coast of Malaysia along with the railway project news discourse as the study of corpora, news discourse from 
the perspective of appraisal theory research attitude, is conducive to understand the interests of Malaysia demands and expectations of cooperation, for the future in China and Malaysia and southeast Asia countries economic and trade cooperation to provide new research perspective and enlightenment. Therefore, it can be found out how the project was viewed at the top and grassroots level in Malaysia [5].

Ding studied the progress and challenges of China's participation in railway construction in Southeast Asia. In recent years, China has participated in many railways' infrastructure projects with other countries, which have improved transportation connectivity in Southeast Asia and provided new impetus for economic cooperation between China and Southeast Asian countries. However, there are many challenges in this process, such as the complex business environment and negative public opinion. Therefore, building demonstration projects and innovating financial systems are important guarantees for China to participate in the high-quality railway construction development in Southeast Asia. It can be known that this project is of great significance to both China and Malaysia. [6] Zhao and Sun analyzed English-Chinese standards in geological prospecting. For the ECRL undertaken by China Communications and Construction Corporation, British standard system was adopted for the off-line design and corresponding geological prospecting work. This study mainly focuses on the application of British standard in specific geological exploration projects, focusing on the difference between project execution and winning the bid and matters needing attention, which is of guiding significance for undertaking overseas projects in the future. [7] He and Lin studied the asking price behavior of the Malaysian government during the ECRL storm. Firstly, the author makes a theoretical framework for the asking behavior, explains its main concepts, connotation, and the theoretical logic behind it, and further explains the impact of big country competition. Coupled with the logic diagram of effective behavior selection, the author analyses the impact of new imports and exports of three big countries, China, the United States and Japan, on Malaysia's imports and exports. Finally, it concludes that the contradictory attitude of the Malaysian Mahathir government towards the ECRL plan is the manifestation of his asking price behavior. [8] Bai studied the project loan risk and Countermeasures of Ya Wan high-speed railway, and used the bank risk management theory, analytic hierarchy process (AHP), and fuzzy analytic hierarchy process (FAHP). It was found that there is land acquisition, technical, operation, credit, post loan management, political, economic, social, and legal risks. The research adopts a fuzzy analytic hierarchy process, quantitative and qualitative analysis, sorts out and summarizes the risk factors in the qualitative aspect, and evaluates the risk in the quantitative aspect. [9] Wen studied Wen's 'benefit and risk analysis of China Railway's investment in Indonesia's Jakarta high-speed railway'. In the benefit analysis of Jakarta high-speed railway project, the author explained the demonstration effect, long-term economic effect and bilateral relations of China's high-speed railway from three aspects. He often quoted Wen's point of view in the second part: Indonesia granted China a 50-year franchise right, and China made a comprehensive analysis on the degree of profits from it. According to the agreement, the author believes that China Railway will cost the US \$220 million per kilometer in Indonesia. According to the prediction of the Bandung Institute of technology, the average daily passenger flow will reach 44,000 person times after the completion of the Jakarta high-speed railway. According to the average ticket price of Indonesian rupees 200,000 (about RMB 100), the annual revenue can reach Indonesian rupees 32,000 (about RMB 1.6 billion), which is expected to be profitable in six years. Often express a positive attitude towards ECRL's profitability based on Wen's analysis and the specific situation of ECRL. At the same time, according to the similarities and differences between ECRL and Indonesian high-speed railway, ECRL's transportation of oil to China can have more interest impact on China. Therefore, it is concluded that ECRL will make both sides mutually benefit [10].

This paper will introduce the negotiation process of this project, analyze the media evaluation, the possible difficulties encountered in this project's implementation process, and the countermeasures. In addition, we will make a comparative analysis of this project and the Jakarta Bandung High-Speed Railway Project to look into the bright future of this project. 


\section{The negotiating process of the ECRL}

As shown in Table 1, the negotiations on this project went through a long process. After six years of operation, $1 \mathrm{MDB}$ was exposed to massive losses in 2015, and dark corruption scandals have also been exposed. Mr. Najib, along with his family and several Allies, is accused of using public funds to buy real estate and luxury goods. That includes $\$ 4.5$ billion in global purchases of art, luxury yachts, and Internet movies. Mr. Najib kept denying the allegations until they boiled over in 2018. That same year, the National Front's defeat in the general election ended its 61 years in power, and Najib resigned as Umno chairman. Tun Mahathir bin Mohamad was inaugurated as prime minister. The new Malaysian government believes Chinese companies were involved in the massive money and power scandal surrounding the 1MDB fund. Malaysia's finance ministry had earlier suspended three major Chinese construction projects - including two gas pipeline projects and a railroad project that is ECRL. He warned that large Chinese investment projects would sharply reduce opportunities and increase competition from local contractors. Political analysts are also concerned that the effects of Chinese investment projects will benefit only the upper elite of Malaysian society, not the general population. Therefore, Mahathir suspended the ECRL, citing the national interest. At the end of his visit to Beijing, Malaysian Prime Minister Mahathir Mohamad confirmed to Malaysian journalists that three Chinesefunded projects totaling $\$ 22$ billion will be cancelled until the country finds a way to repay the loans." I have explained (to Chinese leaders) why we can't build Malaysia's ECRL," he said." Because we need to borrow too much money, we can't afford it, we can't pay it back, and Malaysia doesn't need these projects right now ...... Our problem now is to solve the deficit problem."

Table 1. Timeline of Negotiation Process

\begin{tabular}{|c|c|}
\hline Time & Negotiation Content \\
\hline 2015 & $\begin{array}{l}1 \text { Malaysia Development Berhad exposed to a dark corruption scandal within the } \\
\text { company. }\end{array}$ \\
\hline 2018 & $\begin{array}{l}\text { Allegations of corruption against Najib intensify BN loses in general election The } \\
\text { same year Newly installed Mahathir suspends the China-Malaysia railroad project. }\end{array}$ \\
\hline $\begin{array}{c}\text { August } \\
2018\end{array}$ & Mahathir says the Malaysian side has received an understanding from the Chinese side. \\
\hline $\begin{array}{r}\text { Janu } \\
201\end{array}$ & starts talks on the Sino-Malays \\
\hline $\begin{array}{c}\text { February } \\
2019\end{array}$ & $\begin{array}{r}\text { The Malaysian side says the projec } \\
\text { disc }\end{array}$ \\
\hline April 2019 & $\begin{array}{l}\text { Mahathir visits China to complete talks with China on the Sino-Malaysian railroad } \\
\text { April 12, } 2019 \text { Malaysia announces resumption of Sino-Malaysian railroad project } \\
\text { with China. }\end{array}$ \\
\hline
\end{tabular}

In August 2018, Mahathir said the authorities had understood from the Chinese side that they did not oppose the cancellation of the projects, including the ECRL, and said he was studying whether to postpone the Chinese-funded ECRL. In January 2019, Mahathir again said the Malaysian government would negotiate with China to scale down the ECRL and continue with it. In February, Mahathir said the authorities talked with the Chinese side for negotiations and could not disclose any details. The following month, Malaysian Finance Minister Lim Guan Eng said Malaysia hoped to complete negotiations on the ECRL before Mr. Mahathir visited China in April. Earlier, Mr. Dane told the media that negotiations between Malaysia and China on a contract for the ECRL were nearing completion. An agreement was expected to be reached in early April. The new agreement could result in cost savings of more than RM10 billion. After months of negotiations between the Malaysian and Chinese governments and the companies involved, Malaysia announced the resumption of the ECRL on April 12, 2019, with the signing of a supplementary agreement between Malaysia Railways and 
Volume 16 (2021)

China Communications Construction, in which the construction costs of the first and second phases will be discounted by $32.8 \%$.

\section{The local media and public comments}

Since the project's construction, it has gone through the stages of construction, suspension, and resumption of work. The different construction stages reflect the attitudes of the Malaysian authorities and the public towards the project. At the same time, Malaysian mainstream media reports directly affected the local public perception of this.

According to statistics, there were 85 reports on the Belt and Road in the four mainstream Malaysian media in 2018, of which 76 directly mentioned the Belt and Road and 18 mentioned the ECRL. Among them, 58 reports expressed a positive attitude, accounting for $68 \%, 23$ reported neutral attitudes, accounting for $27 \%$, and 4 reported negative attitude, accounting for $5 \%$.

Table 2. Mainstream Media Reports on the Belt and Road in Malaysia

\begin{tabular}{|c|c|c|c|}
\hline Attitude & Positive & Neutral & Negative \\
\hline Quantity & 58 & 23 & 4 \\
\hline Percentage & $68 \%$ & $27 \%$ & $5 \%$ \\
\hline
\end{tabular}

On the whole, they hold a positive attitude towards it. They believe that for Malaysia, the ECRL will connect the important towns on the east coast of Malaysia with the economic center on the west coast, which is conducive to promoting the coordinated development of Malay Peninsula and driving the development of business, logistics, trade and tourism in the areas along the route. This will play an important role in promoting Malaysia's overall economic and social development and will also set a good example for Southeast Asia and even countries and regions related to the belt and Road Initiative. The railway, which passes through several state capitals and Kuala Lumpur, Malaysia's capital and largest city with a population of 1.8 million, is expected to boost Malaysia's GDP by $1.5 \%$. In addition, during the development period, the project will create more than 80,000 local jobs, which will be stable at more than 6,000 jobs after the project is put into operation, and train more than 3,000 talents for railway construction and operation in Malaysia.

The construction of the project will also increase China's presence in Malaysia. Malaysia is an integral part of the "Belt and Road" maritime route from Southeast Asia through India and the Middle East, facing the South China Sea in the east. Near the port of Kuantan, plans are also under way to build an industrial park in cooperation with China. The strengthening of Chinese color is not only seen in eastern Malaysia. Malaysia has decided to provide vehicles for the railway linking Kuala Lumpur and Klang to Chinese companies. In places such as the southern state of Johor, Chinese-led development projects are increasing. If economic dependence on China increases, it is likely to show more understanding of China's claims in the political arena. At the Asean foreign ministers' meeting in Manila, Malaysia expressed support for the framework of a Code of Conduct in the South China Sea to prevent disputes in the South China Sea. If Malaysia becomes more pro-China, China's influence within ASEAN will be further strengthened.

The affirmers of the project from the Malaysian side include the high-level officials of the two sides and the grass-roots level of the Malaysian side. Fishermen, for example, say the project has not only boosted tourism but also facilitated the development of their fishing industry. The entrepreneur commented from a business perspective, saying that the project's construction would provide a way for his goods to be transported across the region, making a dream come true for many years to sell his chips in boxes directly to central and southern Malaysia. These individual evaluators stand on the community of interests they represent and communicate the common message with their own voice. They see that the project can meet their interests and bring them benefits, support the project construction, and be willing and willing to participate in the project construction. 


\section{Discussion}

\subsection{Difficulties during the Implementation of ECRL and Suggestions}

There are some difficulties encountered during the implementation of the project. First of all, according to the survey, about $70 \%$ of the whole line is private land. The workload and difficulty of land acquisition and demolition vary among the states, especially in the last section, Selangor, which has the most considerable workload, directly affecting the project implementation schedule.

Secondly, Malaysia has imposed restrictions on China's general labor market. However, the main labor export in Malaysia comes from Indonesia, Bangladesh, Myanmar, and other places. The degree of diligence and technical level of the workers is lower than the relevant domestic professionals. At the same time, Malaysia is a country where many religions coexist. The state religion is Islam, Buddhism, Hinduism, Christianity and so on. Muslims account for 55\% of the total population. If Chinese management thinking is used to manage local employees, customs and cultures may clash.

Additionally, the ECRL works according to local standards and the online works according to Chinese standards, while most of the construction of the Malaysia railway is carried out according to British standards and has formed its own set of the standard model. China has become the world's second-largest railway operator, but this legal system is not well known and has not been widely recognized internationally. In some engineering fields, there are also standards crossover and fusion. Therefore, how to let Malaysia recognize the Chinese standard is a significant, complex problem.

Last but not the least, the ECRL crosses the Genting Plateau on its way. The tunnel is about 16 kilometers long and has a maximum burial depth of about 750 meters. This puts forward high requirements for tunnel construction organization, disaster prevention and rescue design, ventilation and drainage design. At the same time, it has the characteristics of difficult construction organization, high technical content and high HSE requirements.

To this end, we propose the following proposals:

Firstly, the project organizer should carry out an in-depth and meticulous field investigation of land expropriation, make clear the unfavourable factors in advance, carefully analyze and timely solve the parts that affect the production and life of people along the line and resolve the contradiction between enterprises and local areas. On the premise that labor conditions are met, local people along the railway should be preferentially employed to participate in railway construction to reduce construction obstruction and ensure the smooth progress of project construction.

Secondly, adhering to the localization strategy. Take the initiative to familiarize Malaysia's economy, politics, and social culture and respect local laws and social customs. Please pay attention to the localization management of enterprise culture, hire a group of excellent foreign employees, give them technical and operation management training. Only through their transmission of information and ideas can China strengthen exchanges and mutual trust with the Malaysian government.

Thirdly, accelerating the internationalization of China's railway standards and constantly improve their technical level and influence. At the same time, because the engineering interface and implementation method of the existing railway in Malaysia is different from the domestic model, the contractor should hire Malaysian experts and scholars to cultivate interdisciplinary talents with global vision and be familiar with Malaysian laws and practices.

Fourthly, in order to deal with the situation of large amount of water inrush in the tunnel, it is necessary to equip a pumping station with strong pumping capacity to drain water in the tunnel, and a mobile pumping station can be set up to drain water in the tunnel, which can ensure the safety of construction operation to a greater extent. In poor geological area, effective grouting reinforcement can be carried out to ensure the safety of tunnel construction process. Grouting can play the role of reinforcement and water plugging, so it can also reduce the tunnel water seepage to a certain extent. 


\subsection{Comparative Analysis}

To further analyze it's feasibility, here we select a railroad which is also BRL Chinese overseas project: Jakarta Bandung High-Speed Railway Project (here is called High-speed railway for short).

The high-speed railway project is jointly operated by Chinese and Indonesia enterprises and provided with loans by China. The cost of the project is the US $\$ 5.135$ billion. The investment mode is that Indonesia accounts for $60 \%$ and China accounts for $40 \%$. In terms of loan provision, Exim Bank of China bears $75 \%$ of the project's cost. On October 16, 2015, China Railway Corporation signed an agreement with four Indonesian state-owned enterprises in Jakarta to establish a joint venture, which was started in November of that year. The project is expected to be completed within three years. However, due to land acquisition and railway extension, the construction process of highspeed railway projects is slow. Various problems happened in the process of land acquisition by the Indonesian government. China Development Bank refused to issue loans before the completion of land acquisition. The low efficiency of the Indonesian government and insufficient funds are the main reasons for the delay in promoting the high-speed railway project. The high-speed railway project, which was initially successfully bidding in 2015, was not included in Indonesia's national space plan until 2017, and the land acquisition along the line was legalized. In July 2017, the president of Indonesia transferred part of Indonesia's equity in the project to China, so China holds 90\%, and Indonesia's state-owned consortium only needs to provide $10 \%$ of the capital for the high-speed railway project.

In addition to land acquisition, high-speed railway project also faces financial, political and technical problems. In contrast to the ECRL project, the issues faced by both sides are similar.

On March 16, 2016, the Ministry of Transport of Indonesia signed a franchise agreement with the high-speed rail joint venture. According to the agreement, the franchise right of the joint venture to high-speed rail will begin on May 31, 2019, and last for 50 years. According to the agreement, the cost of the project is about 222 million yuan per kilometer. According to the prediction of the chief engineer of China Railway Tunnel Group, the cost of a high-speed railway per kilometer is about 180 million yuan, so that it will be profitable. According to the prediction of the Bandung Institute of technology, the daily average passenger flow in the initial stage of the high-speed railway project is about 44000. If the average ticket price is 200000 Indonesian rupees (about 100 yuan), the annual ticket revenue can reach 3.2 trillion Indonesian rupees (about 1.6 billion yuan). The similar Beijing Tianjin intercity high-speed railway is expected to be profitable six years after its completion. The franchise of the high-speed railway lasts for 50 years. In the long run, the project can achieve greater profits. As mentioned above, we predict that the ECRL in Malaysia will also bring more benefits to the future of both China and Malaysia.

\section{Conclusion}

This paper introduces the Belt and Road Project and the ECRL. Then it analyzes the media evaluation of this project and puts forward the possible difficulties and countermeasures in implementing it. In addition, a comparison analysis is also conducted with the Jakarta Bandung HighSpeed Railway Project to forecast the bright prospect of ECRL. In conclusion, Malaysia must resolve these internal issues of inefficiency, lacklustre productivity, and corruption to compete as a gamechanging port economy on the global stage. The eastern coastal railway will undoubtedly encounter more complicated and changeable difficulties in the implementation process. China Communications Construction Corporation should unify its thinking and strengthen its confidence to make the ECRL a landmark overseas railway project. The ECRL is by far the most significant economic and trade project in the history of China and Malaysia. The implementation of the project is not only the extension of railway facilities on both sides of Malaysia but also another extension of mutual trust and cooperation between China and Malaysia. Taking the Belt and Road Initiative as an opportunity, China and other countries, including Malaysia, will continue to deepen regional cooperation, further increase economic exchanges between countries and elevate cooperative relations to a new height. 


\section{References}

[1] Gong, X. (2020). China's Belt and Road Initiative Financing in Southeast Asia, 77 - 95.

[2] Huang, \& Yiping. (2016). Understanding china's belt \& road initiative: motivation, framework and assessment. China Economic Review (1043951X), 40, 314 - 321.

[3] Malgeri, G. (2019). Malaysia and the Belt and Road Initiative: an agency perspective of the East Coast Rail Link (ECRL) renegotiation process.

[4] Tao Lingxiu. (2020). The Image of China in Malaysian Online media -- Based on the report of East Coast Railway Project in Malaysia Today. Culture and Communication, v.9; No.49 (01), 119 - 122.

[5] Cao Man, \& Wu Hong. An Attitude analysis of news discourse from the perspective of Evaluation Theory: A case study of Malaysia east Coast Railway Project News. Journal of Dongguan University of Technology, 28 (2), 8.

[6] Ding Meng. (2020). Progress and challenges of China's participation in railway construction in Southeast Asia. Innovation, 014 (002), 19 - 28.

[7] Zhao Shuguang, Sun Deke. (2020). Difference analysis of English-Chinese standards in geological prospecting. Engineering Investigation, V.48; No.377 (12), 18 - 25.

[8] He Xianqing \& Lin Yongxin. (2020). Pricing behavior of small and medium-sized countries and investment risk of "One Belt and One Road" project: A case study of Malaysia's East Coast Railway Plan. International Forum (05), 25 - 42+155 - 156.

[9] Bai Fengchao. (2019). Loan risk analysis and countermeasures research of China Development Bank for Ya-Bandung High-speed Railway Project (Master's thesis, Beijing Jiaotong University).

[10] Wen D. (2020). Benefit and risk analysis of China Railway's investment in Indonesia jakarta-Bandung High-speed Railway. Foreign Trade and Economic Cooperation (04), 21 - 24. 